\title{
Biografias transgressoras: Manoel de Oliveira Lima e D.Luís de Orléans e Bragança
}

\author{
Teresa Malatian \\ Universidade Estadual Paulista "Júlio Mesquita Filho"/Franca
}

A biografia nunca esteve ausente das reflexões historiográficas ou das práticas profissionais dos historiadores. Gênero antigo, conservou fronteiras fluídas do domínio literário com o campo do conhecimento histórico, despertando a desconfiança de críticos que lhe atribuíam o estatuto de território sujeito à exaltação tendenciosa de um indivíduo, um grupo ou uma causa. Entre a biografia e a História, um abismo de insegurança e fragilidade diante do problema da verdade da narrativa caminharam pari passu com tentativas de tornar a biografia mais confiável mediante desmistificação e recusa do elogio incondicional ou da crítica demolidora.

O tema envolve reflexões sobre as relações entre o indivíduo e o coletivo no fazer histórico, ao qual Carlyle propôs uma resposta quando na primeira metade do século XIX serviu-se da biografia para questionar a linearidade tradicional da história factual. Para dar à História volume e profundidade, utilizou o herói como meio de expressão do fluxo caótico e aleatório da vida e com tal intuito produziu estudos notáveis sobre John Sterling e Cromwell. O herói individual, objeto de exaltação, foi por ele considerado expressão de sua época e com esta concepção a História se tornou o campo de afrontamento de personalidades heroicas, cada uma com sua função profética enquanto encarnação das forças do Espírito, entendidas como religião, o fator principal na vida do homem. O herói demiurgo seria capaz de dar sentido à história e forçar o destino.

Nos cinquenta anos que se seguiram, duas interpretações viriam dar novas respostas à problemática da construção de biografias pelos historiadores. Michelet, ao biografar Joana d'Arc, privilegiou na reflexão histórica os valores coletivos, expressos pelo povo, delegando aos indivíduos o papel de 
representantes de paixões coletivas. Com outra concepção historiográfica, Marx colocou no centro da história as classes sociais reduzindo o papel dos indivíduos no discurso histórico ainda que deles se ocupasse ao analisar o 18 Brumário de Luís Bonaparte.

Outras respostas foram dadas ainda no século XIX por historiadores que, a exemplo de Taine e Renan, percorreram o século do nacionalismo preocupados com a concepção do grande homem como produto da raça, do meio, do momento, o homem-partícula, o átomo social que tributou ao romantismo a mudança de sentido da biografia. A tensão entre indivíduo e sociedade trabalhada nas biografias visava encontrar no destino individual a força do contexto geográfico, cultural, histórico, social. Em tal perspectiva, o herói romântico seria realizador dos desígnios da Providência e do progresso.

Com os historiadores dos Annales, a História se firmou como território dos sujeitos coletivos, dos grande movimentos econômicos e sociais. No entanto, o grupo fundador da revista não realizou uma virada antibiográfica. Lucien Febvre apontou os problemas, perigos e tentações da biografia individual mas escreveu Um destino, Martinho Lutero e A religião de Rabelais. Sua contribuição aos estudos biográficos destacou trajetórias individuais, centrando a análise na utensilagem mental específica de um período e de um grupo de homens. A abordagem abria- se para a temporalidade ampliada, o econômico, o social, as mentalidades, os atores coletivos mas reservava um espaço e um protagonismo aos sujeitos individuais.

Entre os historiadores formados na tradição dos Annales destaca-se décadas depois a obra de Jacques Le Goff ao biografar São Luís e São Francisco de Assis. Em lugar da linearidade factual da curta duração centrada na cronologia do tempo curto da vida do indivíduo, enfatizou o contexto econômico, político, social, cultural no qual se insere e desenvolve uma vida, esclarecedor de trajetórias num campo de possibilidades de escolhas no qual se exerce a ação individual.

A menor ênfase na história quantitativa e serial com seus ciclos e movimentos demográficos, o 'retorno' do político na Historiografia já nas décadas finais do século XX, reabilitado juntamente com o da curta duração do evento e da narrativa, possibilitaram um novo interesse pela escrita de si, pela vida cotidiana, dos costumes, dos homens comuns. O interesse pelo indivíduo e seu papel na história, em confronto com a sociedade, coloca para 
o historiador do gênero biográfico a questão da liberdade, das relações entre fenômenos coletivos e estratégias e comportamentos individuais traduzidos em escolhas que não são inapelavelmente determinadas pela sociedade.

Nos anos 1980-90, o giro linguístico, o florescimento da história narrativa, a valorização do indivíduo e do seu protagonismo social abriram novas perspectivas para além das estruturas e das classes sociais. Mais descritiva e narrativa que analítica, enfocando o homem mais que as circunstâncias, incorporando aportes da literatura, a Historiografia com seus diversos 'retornos' abriu espaço privilegiado para a biografia.

Considerada por muitos historiadores como uma arte ${ }^{1}$, a biografia exige do pesquisador um cuidado que não se distancia daquele devido a qualquer outro tipo de discurso histórico, característico da disciplina histórica: a compreensão e a aproximação do personagem até o ponto de saturação, para que se possa escrever sobre ele. E, sobretudo, o trabalho crítico sobre testemunhos diferentes e contraditórios que ao ampliar o enfoque analítico, permitam ao historiador alcançar aspectos desconhecidos de uma vida e ultrapassar a opacidade que ela teve para seus contemporâneos. Entre histórias de vida individuais e prosopografias (notícias biográficas individuais confrontadas para que mediante amostras se possam estabelecer tipos, salientar traços comuns), o gênero se mantém próximo da literatura e por isto mesmo, a solicitar atenção redobrada do historiador na construção da narrativa.

Da literatura, tem sido incorporadas às biografias técnicas e recursos estilísticos como o flasback, elementos ficcionais mesclados à informação seguramente documentada, incorporação de detalhes pitorescos e da vida cotidiana, estilo cuidado, narrativa fluída, num diálogo em busca com o hipotético leitor visando cativá-lo para a vida que se desfralda ante seus olhos. Nem é de se desprezar a prática de deixar fluir a visão de mundo do escritor ao caracterizar o personagem visando a produção de um efeito de realidade. ${ }^{2}$ Aos historiadores e preservadores da disciplina histórica, cabe no entanto a tarefa de eliminar a mescla entre biografia e romance, de estabelecer referências documentais e empíricas seguras, de preocupar-se com a verdade ou as verdades, recorrendo às palavras 'provavelmente', 'talvez', 'pode-se presumir', 'acredita-se que', etc.

Não há como eludir a forma narrativa e cronológica que permite acompanhar a trajetória do personagem e estabelecer marcos temporais unindo 
contexto e trajetória individual. Persiste nessa construção discursiva o problema metodológico dedesvendar os múltiplos fios de conexões para revelar dimensões de problemas da pesquisa não perceptíveis nos enfoques macroscópicos. A abordagem dos sentimentos, do inconsciente, da cultura, da vida privada, do cotidiano, permite ao pesquisador considerar o biografado como um lócus de interação de determinações relacionais. Com ela torna-se viável alcançar o biografado para além de uma constância a si mesmo verdadeiramente inatingível, para dar conta de um sujeito fracionado e múltiplo, tal como se apresenta aos olhos sensíveis do historiador.

Esse direcionamento possibilita o estabelecimento de articulações "entre vida pública e vida privada, entre cotidiano e não-cotidiano, entre atos racionais e motivações irracionais"3. Eixos analíticos importantes podem vir a ser traçados em torno de temáticas como família, estudos, trabalho, militância, produção intelectual que iluminem a personalidade do biografado.

Uma das soluções para a tensão entre o indivíduo e a trama social é apresentada por Franco Ferrarotti em Histoire et histoires de vie. Suas reflexões se dirigem para a abordagem estrutural das relações entre indivíduo e sociedade nos estudos biográficos, ao considerar que "uma vida é uma prática que se apropria das relações sociais (as estruturas sociais) as interioriza e as transforma em estruturas psicológicas por sua atividade de desestruturação-reestruturação"4. Se o enquadramento estruturalista parece hoje excessivamente limitador da compreensão da autonomia do sujeito individual, convém salientar que Ferrarotti minimiza sua rigidez ao apresentar a vida humana como "síntese horizontal de uma estrutura social", porém recusa o determinismo mecânico entre história social e história de vida. Atribui ao sujeito um papel ativo ao insistir em que "longe de refletir o social, o indivíduo se apropria dele, o mediatiza, filtra e retraduz projetando-o em uma outra dimensão (...), a de sua subjetividade", alcançando assim a definição do indivíduo como "síntese individualizada e ativa de uma sociedade" ${ }_{5}$. Se levada em conta esta proposta metodológica, o relato biográfico deixaria de ser uma série de anedotas para centrar-se na ação social do indivíduo, na sua relação com a sociedade, análise que Ferrarotti sugere a partir de ancoragens antropológicas e sociológicas. Nessa perspectiva a biografia será entendida como uma leitura do social na qual se estabelecem relações entre um indivíduo e o tempo sociohistórico, articulação entre história coletiva e história de uma vida. 
Esta é a principal ênfase da releitura do gênero biográfico realizada por Pierre Bourdieu desde a publicação do texto hoje clássico sobre a 'ilusão biográfica', apresentado nas Actes de la Recherche em Sciences sociales e republicado em Usos e abusos da História Oral ${ }^{6}$. O núcleo de sua análise reside na teoria da práxis construída em relação aos campos, ou seja, os 'domínios específicos da vida social' nos quais ocorrem relações pautadas pelas atribuições de poder construídas em função da presença de capitais materiais ou simbólicos. Em suas diversas obras, Bourdieu alerta para a inexistência de uma "sequência cronológica e lógica dos acontecimentos e ocorrências da vida de uma pessoa", numa linha que postula a linearidade progressiva e a causalidade como construções a posteriori. Em 1968, quando publicou O ofício de sociólogo, com Passeron e Chamboredon, Bourdieu já se ocupava desse tema, que burilou ao longo de sua obra até chegar ao conceito de ilusão biográfica, que encerra a compreensão de que o sentido de causalidade e de coerência tão necessários à construção de uma biografia constituem algo atribuído às ações humanas. Considerando que o sentido global do sujeito escapa até mesmo à sua auto-percepção, resta aos analistas recorrer à objetivação do habitus que decorre da interiorização do social pelo indivíduo, de modo estável porém sujeito a modificações. Habitus se torna um conceito a ser operacionalizado na biografia por revelar sistema de disposições socialmente constituídas, que em seu constante movimento estruturante, está na origem e unifica as práticas dos agentes sociais. $^{7}$

As marcas distintivas estão presentes no nome, no biológico e nas ações dos indivíduos, definindo trajetórias nos campos nos quais se insere. Sua presença como diretriz da pesquisa permite situar os agentes sociais - os indivíduos - socialmente, pela trajetória diacrônica nos diversos campos. Tal procedimento metodológico permite escapar à ilusão biográfica pela construção de certos traços pertinentes em termos de estratégias e injunções ocorridas em cada campo, que afetam diretamente os indivíduos, ao se movimentarem pelos traços do habitus, os quais incluem relações de poder.

Tais proposições de âmbito sociológico permitem uma sofisticação da pesquisa e requerem do historiador uma tomada de posição sobre o protagonismo individual e o grau de autonomia dos sujeitos individuais ou sua vulnerabilidade diante das forças operantes nos campos nos quais eles se movem, testemunho da complexidade do trabalho de pesquisa biográfica. 
Giovanni Levi em Os usos da biografia estabeleceu importante diálogo com Bourdieu para afirmar a irredutibilidade dos indivíduos e de seus comportamentos a sistemas normativos gerais, embora aceite o estabelecimento de uma superfície social da ação dos indivíduos. Ainda assim, há que atentar para os elementos contraditórios, a fragmentação dos tempos e ritmos da vida dos indivíduos, pelos movimentos incessantes de retornos, idas e vindas que ocorrem numa rede de relações nas quais os indivíduos se definem. Levi aproxima a teoria sociológica da valorização da ação individual ao analisar o jogo entre indivíduo e grupo, entre biografia e contexto, reconhecendo a existência de determinações às quais o indivíduo não consegue fugir, mas distinguindo um espaço de atuação individual que é o espaço da liberdade e se traduz em escolhas, as quais ao evidenciarem incoerências e conflitos, promovem a mudança social.

Com tais referentes, foi empreendido o estudo biográfico de dois transgressores, Manoel de Oliveira Lima, historiador e diplomata brasileiro (1867-1928), e o príncipe D. Luís de Orléans e Bragança (1878-1920) cujos resultados permitem problematizar a escrita biográfica, na medida em que os biografados atuaram no campo da política e escreveram obras portadoras de linguagens políticas.

\section{O Historiador-diplomata}

Manoel de Oliveira Lima foi objeto deste estudo biográfico, mais precisamente biobibliográfico, motivado pela sua obra e pela trajetória de vida de grande interesse para a compreensão das relações entre história e diplomacia durante a Primeira República. Produziu obras sobre história política, econômica e social sobre Pernambuco e o Império brasileiro, além de estudos de história diplomática. Exerceu com destaque o jornalismo, inserindo-se nas principais polêmicas políticas de sua época, tendo como centro de interesses as relações do Brasil com os Estados Unidos e a política do pan-americanismo.

Nesta pesquisa, foi preciso navegar na contracorrente dos estudos que privilegiam a carreira diplomática tumultuada e apresentam como característica o estilo laudatório. Poucos são os trabalhos incidentes sobre sua extensa obra histórica. Fernando da Cruz Gouvêa, no trabalho de maior amplitude sobre o historiador-diplomata - Oliveira Lima: uma biografia 
- realizou um estudo biográfico que, embora apoiado em documentos significativos e inéditos, segue esta tendência. O mesmo se pode dizer do estudo elaborado por Gilberto Freyre, intitulado Oliveira Lima: D. Quixote Gordo , onde o retrato psicológico emoldurado pelo regionalismo sobrepõe-se à análise de sua obra. Um trabalho de maior reflexão historiográfica é o de Barbosa Lima Sobrinho - Oliveira Lima: sua vida e sua obra - onde é apresentado um panorama das obras históricas do autor, relacionadas com algumas de suas condições de produção. A inovação começou a se esboçar com a obra Estrutura social da república das letras, onde Antônio Luís Machado Neto destacou Oliveira Lima em estudo sociológico das coteries que marcaram a vida intelectual brasileira de 1870 a 1930, revelando assim uma rede de relações na qual ele se envolveu. ${ }^{8}$

A relação do intelectual-historiador com a política norteou a perspectiva de unir a trajetória biográfica à análise de sua obra, ultrapassando assim a análise dos bastidores que conduz às intrigas vigentes no mundo da diplomacia para verificar a construção de uma obra com importantes aportes às questões da nação, do Estado e da identidade nacional. O enfoque revelou um historiador engajado no serviço diplomático, com fortes vinculações junto à oligarquia pernambucana, trânsito em altas esferas da administração e reconhecida projeção intelectual.

Analisar sua trajetória significou desvendar também articulações entre as oligarquias regionais e o poder central na Primeira República, tendo como intermediação o Ministério das Relações Exteriores enquanto abrigo para intelectuais que utilizavam a carreira diplomática de modo a tornar possível sua dedicação às letras.

A análise solicitou a compreensão de aspectos da sociabilidade em vigência no mundo da diplomacia, uma vez que apenas a identificação das relações entre o Itamaraty e a classe dominante não seria suficiente para explicar as relações de poder ali presentes. Nesse sentido, A sociedade de corte de Norbert Elias forneceu subsídios ao estabelecer alguns comportamentos e atos normativos que podem ser identificados no serviço diplomático, pautado por um código de boas maneiras, por certos traços que conferem distinção. Identifica a diplomacia como campo de expressão dos padrões da sociedade de corte: "a adequação perfeita das atitudes, dos gestos judiciosamente calculados, das frases com vários sentidos", ou seja, 
a forma específica de racionalidade que se tornara para os membros desta sociedade numa espécie de segunda natureza que eles sabiam utilizar com facilidade e segurança e que - tal como o controle da afetividade que postulava - era um instrumento indispensável à competição permanente pelo estatuto e pelo prestígio $^{9}$

tais características da sociabilidade na diplomacia constituíam elementos importantes da identidade do diplomata e atuavam em sua visão de mundo como dinâmica de distinção.

Com esses referentes foi possível analisar a inserção de Oliveira Lima no mundo da diplomacia enquanto campo social, bem como em outros espaços de sociabilidade nos quais atuou, utilizando-se o conceito de espaço social no qual se dá a trama de relações configuradas em diferentes campos que informam a produção e a difusão cultura $1^{10}$ para identificar um sentido nesses espaços de sociabilidade constituídos segundo redes de relações que resultam não apenas em fronteiras geográficas e afetivas, mas em seus desdobramentos em termos de vínculos amistosos ou hostis em torno de uma dada visão de mundo e de posições de poder que os agentes neles ocupam. Esse campo de produção da história guarda assim relações com escolas, associações de intelectuais, revistas, salões, livrarias, enfim, locais de produção e circulação de ideias.

A visão de mundo produzida num dado espaço social ou espaço de sociabilidade revela-se também no consumo de objetos culturais e apreciações estéticas que implicam diferenciação e fronteira entre grupos sociais, portanto atuam como relações de poder, cuja constatação pode refinar a compreensão das lutas ideológicas que envolvem as classes sociais pela definição e imposição de uma visão de mundo, explicando posições divergentes assumidas no interior de uma dada classe. Esta tarefa organizadora do mundo das representações e dos símbolos, essencial para a obtenção do consenso, estabelece interação, legitima problemas sociais considerados dignos de serem discutidos, tornados públicos e até oficializados pela ciência.

No âmbito deste trabalho, a análise levou em conta tanto o campo político específico, onde são produzidos problemas, programas, análises, comentários, conceitos e ações diversas, como os campos intelectuais que deram uma peculiar configuração à trajetória de Oliveira Lima: associações de

\section{Maracanan}


historiadores e literatos, universidades. O desafio foi colocado em termos de se verificar como Oliveira Lima, dadas as posições tomadas nos diversos espaços de sociabilidade, construiu uma obra decorrente de sua percepção das possibilidades disponíveis, das escolhas e dos interesses associados e eles. Decorreu daí a necessidade de se mapearem as relações que uniram Oliveira Lima aos diferentes espaços de sociabilidade, suas alocações e seus deslocamentos durante o período em que sua produção esteve orientada pelo ofício de diplomata, ou seja, até sua aposentadoria em 1913, período em que construiu relações organizacionais e simbólicas relevantes para sua trajetória individual e que estão presentes na sua obra.

A análise passou pela compreensão vigente sobre o saber histórico, constituído como um campo específico do conhecimento a ser recortado em território do historiador. A atuação de Oliveira Lima como historiador ocorreu num momento em que "a história lutava por demarcar sua especificidade, distinguindo-se e aproximando-se, ao mesmo tempo, da literatura e dos ensaios político-sociais". ${ }^{11}$

O campo da produção historiográfica não apenas definia-se em termos de uma dada concepção do saber histórico mas também das relações desse saber e de suas condições de produção com o Estado e com o campo da política. As questões referentes à identidade nacional eram colocadas como legítimas no debate intelectual, refletindo-se em estratégias de produção cultural centradas na imprensa e em determinadas matrizes institucionais, acadêmicas e governamentais. Daí a importância de se analisar os fatores que entraram na construção da história por Oliveira Lima, não apenas sua trajetória pessoal, mas sobretudo sua filiação institucional ao Itamaraty e às associações de que fez parte, aquelas especificamente voltadas para a produção do conhecimento histórico, entre elas o Instituto Histórico e Geográfico Brasileiro e o Instituto Arqueológico e Geográfico Pernambucano, além da Academia Brasileira de Letras (ABL) que reuniu historiadores entre os literatos.

A síntese a ser alcançada na análise por meio da construção do historiador-diplomata constituiu um desafio: superar o repertório de detalhes pitorescos e dados biográficos sobrepostos à compreensão da obra e à sua inserção num dado momento histórico. A serenidade de crítica e de abordagem para escapar do panegírico, da apologia ou da crítica demolidora, esteve desde o início do estudo equacionado por tratar-se de um autor polêmico 
e polemista, com posições mutantes e contraditórias assumidas ao longo de sua vida, sempre acompanhadas de alta carga emocional e mobilizadora em defesa de suas ideias.

A noção de campo desenvolvida por Bourdieu foi utilizada para a análise do público a que se destinou sua obra, da repercussão alcançada, das interpretações e críticas recebidas de leitores qualificados como pares, tendo como diretriz sua inserção numa dada realidade cultural que comporta uma dupla escritura: a das regras teórico-metodológicas de sua escrita segundo o instrumental científico e literário em vigência e a de suas relações com um conjunto de referências políticas consideradas válidas no momento de sua produção ou de sua apropriação pelos leitores. Supôs-se assim que a obra histórica só poderia ser compreendida se analisada a partir do momento histórico e dos campos sociais em que ocorreu sua criação.

O conceito de colégio invisível aqui operacionalizado com base na correspondência e nos artigos e resenhas de obras divulgadas em jornais e periódicos foi também útil para a compreensão mais refinada do conceito de espaço de sociabilidade enquanto universo de diálogo do autor. Segundo Glezer, constitui um

grupo de pessoas, em cada ramo do conhecimento e suas subdivisões, razoavelmente bem relacionadas entre si, encontrando-se em conferências, permutando publicações e colaborando em instituições de pesquisa. Constituem um grupo de poder, em níveis locais e nacionais, controlando instituições, prestígio pessoal, destino de novas ideias e orientação para abordagem de novas áreas. ${ }^{12}$

Trata-se de um grupo relativamente fechado, cujo acesso é obtido por procedimentos ligados à influência e ao mérito atribuído à produção de um autor e às suas inserções em campos sociais determinados, tais como instituições culturais e academias.

A análise levou em consideração características específicas do mundo das letras da Primeira República, no qual Oliveira Lima inseriu-se por meio de suas obras históricas e do jornalismo. Trata-se de um campo social onde predominavam as coteries e igrejinhas literárias, caracterizadas pelas atitudes de apoio mútuo e choques entre grupos rivais, pela dinâmica do "fogo cruzado

\section{Maracanan}


dos elogios mútuos dentro do mesmo grupo e de ataques também cruzados dirigidos aos grupos rivais". ${ }^{13}$

Era o mundo da polêmica literária, que abrigava quase sempre razões políticas, veiculada pelos jornais em elogios derramados aos amigos e em clamores por justiça brandidos contra os inimigos. Oliveira Lima forneceu inesgotável fonte para o bombardeio, que incidia não apenas sobre suas obras e posições assumidas, mas alcançava também sua aparência física. A imprensa da época é especialmente rica em artigos bem como em caricaturas que configuravam o perfil de D. Quixote Gordo consagrado por Gilberto Freyre, traçando uma figura grotesca para os padrões vigentes na diplomacia normatizada pelos códigos de estética da sociedade de corte. O jogo de interesses políticos e de disputa por cargos no serviço diplomático e sobretudo as diferentes posições assumidas perante a condução da política externa deixavam assim de ser uma mera intriga de bastidores para alcançar um público mais amplo, que acabava por legitimar uma polêmica cujos motivos nem sempre eram explícitos.

A questão estava colocada em termos de se verificar como Oliveira Lima, dadas as posições tomadas nos diversos campos sociais ou espaços de sociabilidade, construiu uma obra decorrente de sua percepção das possibilidades disponíveis nos mesmos, das escolhas entre elas e dos interesses associados à sua posição nos campos. Daí a necessidade de se mapearem as relações que uniram Oliveira Lima aos diferentes espaços de sociabilidade, suas alocações e deslocamentos pelos campos sociais durante o período em que sua produção esteve orientada pelo ofício de diplomata, considerando-se que ao longo de sua vida construiu relações organizacionais e simbólicas que constituem sua trajetória individual e que estão presentes na sua obra.

\section{O Peregrino de Impérios}

O estudo sobre Oliveira Lima sedimentou um procedimento metodológico e reafirmou as dificuldades de pesquisa biográfica, porém muito ampliadas no estudo sobre a vida e obra de D. Luís de Orléans e Bragança. Por se tratar de membro da Família Imperial Brasileira, a reunião de informações e documentos assumiu dimensões desencorajadoras, que revelaram a existência de um controle intenso da memória pela família e pelos grupos aos quais 
ela pertence. A sedimentação de uma memória histórica laudatória, ainda mais cristalizada e pertinaz que a de Oliveira Lima, dificultou o acesso a informações inéditas e à revisão historiográfica. Os conflitos de opinião e as batalhas da memória envolvem aspectos relevantes para esta Família dividida em torno de questões de legitimidade política e disputa de bens. Inevitáveis a discrição, o sigilo e a liberação a conta-gotas de informações parcimoniosamente filtradas para impedir interpretações que deslustrassem a história 'oficial', neste caso, ainda por escrever. Mais que no primeiro estudo, esteve presente a impossibilidade de cobrir com detalhes muitos aspectos da trajetória de uma vida. As relações entre o individual e o coletivo adquiriram novos contornos na prática historiográfica a ser autorizada.

Uma questão de fundo norteava a pesquisa: qual o lugar do Império na memória política brasileira? Após o 15 de novembro de 1889, ela se tornou meramente simbólica ou resultou de uma interação entre os defensores da ordem imperial e os partidários da ordem republicana? A busca de resposta forjou o eixo articulador entre o indivíduo biografado e o momento histórico que viveu, em toda sua complexidade, de 1878 a 1920.

As circunstâncias da queda do Império ajudaram a consolidar na historiografia a versão republicana de que ela ocorreu sem resistências e de que a monarquia teria sido derrubada como um 'fruto maduro' que se desprendeu da árvore. A metáfora elaborada numa carta pelo viajante francês Max Leclerc em 1890 teve vida longa por exprimir a interpretação da corrente política republicana vencedora, embora limitada em sua compreensão do processo histórico amplo e das forças e interesses envolvidos. ${ }^{14}$ Aos republicanos era útil minimizar as resistências ao novo regime, acesas desde o primeiro momento e junto com o regime decaído sepultar a memória da Família Imperial. O apagamento das resistências à República foi uma constante até os anos 1970 na Historiografia.

Na última década, a vida dos membros da Família Imperial tem despertado interesse dos historiadores, notadamente para a construção de biografias. Há um renovado movimento historiográfico que atinge personagens desconhecidos, revisões e novas abordagens. Entre elas, salienta-se o estudo de Roderick Barman, Princesa Isabel do Brasil, publicado no Brasil em 2005. A obra se individualiza por analisar a vida da princesa Isabel a partir de uma perspectiva de gênero na qual insere algumas páginas sobre a vida dos seus 
três filhos, entre eles D. Luís. Sua interpretação da personalidade e da atuação do biografado, herdeiro político da mãe, é de que se tratava de "um ativista; ambicioso e voluntarioso, encarava o mundo como algo a ser conquistado", e foi considerado pelos pais como o único dos seus filhos " capaz de manter a causa da Monarquia no Brasil”. Teria no entanto fracassado pela debilidade do movimento monarquista, incapaz de renovar suas lideranças. ${ }^{15}$

Além das batalhas da memória, outro obstáculo dificulta o trabalho do historiador interessado na construção de biografias do núcleo da Família Imperial: a dispersão dos documentos. O cataclismo da queda do Império e do exílio, com sua consequente fixação na França, havia criado uma distância física entre os pesquisadores e os documentos preciosos conservados no Castelo d'Eu, na Normandia. Esta situação começou a ser revertida por ocasião do Centenário da Independência e da revogação do banimento da Família Imperial na década de $1920^{16}$. O trabalho de Alberto Rangel, a convite de D. Pedro de Orléans e Bragança, primogênito da Princesa Isabel e único de seus filhos que lhe sobreviveu, iniciou o inventário dos famosos baús, publicando a seguir em 1939, em dois volumes, a relação sumária da documentação que ali encontrou. Sobre os achados e seus métodos de arquivista, que hoje escandalizariam os historiadores pela concepção preservacionista, as descrições são eloquentes:

Encontrei salvos da cambalhota do exílio trinta e duas caixas enormes de folha a estourarem com os papéis do arquivo imperial. Se tivesse ficado na Quinta ou em Santa Cruz, o seu destino seria o das respectivas sentinas (......). Por insinuação do Príncipe comecei pelo Paraguai. Ao filho do último conde d'Eu devia preocupar esse país, que lhe pesava na herança do descendente direto e imediato do Marechal do exército brasileiro (......) Depois voltei à massa dos documentos em cujo veio se desenrola a nossa história. E os períodos anteriores a 1808, a 1822 e a 1831 lá os deixei peneirados e fixados na ordem à cronológica cujo critério se impunha para uma primeira e mais rápida organização da seara.Pode V. avaliar quanto trabalhei. Desamassei, estirei, li, escolhi, rejeitei... O material é importante se bem que a bagaceira sem elemento algum histórico seja muita. 
Tinha em conta a importância de seu trabalho no "mundo dos documentos cuja insignificância ou importância tive de sopesar, para que se apurasse o que de aproveitável existe para o nosso passado no patrimônio do neto do Magnânimo"17.

Pelo relevo dado por Rangel à documentação sobre o Primeiro Reinado fica evidente sua concepção de História confinada a um passado remoto. Parou por ali sua curiosidade e o arquivo do Segundo Reinado não foi trabalhado por ele. No mesmo documento partilhou com o amigo Afonso de Taunay sua idiossincrasia: "Quanto à época do segundo reinado a messe há de ser maior. Não tive tempo de esmiuçá-la, tempo é modo de dizer, não tive estômago"18. O resultado do trabalho de Rangel consistiu na publicação pela Biblioteca Nacional do Inventário dos documentos do arquivo da Casa Imperial do Brasil existentes no Castelo d'Eu, em 1939, apresentado como uma contribuição de D. Pedro de Orléans e Bragança - primogênito da Princesa Isabel e do Conde d'Eu - à comissão do Centenário da Fundação de Petrópolis. Após a Segunda Guerra Mundial ocorreu uma divisão do arquivo, sendo parte dele direcionado para o Museu Imperial de Petrópolis e para o Palácio do Grão-Pará e outra confiada ao ramo dos descendentes de D.Luís.

A questão dinástica conduziu a historiografia sobre a Família Imperial e com ela cristalizou-se um perfil biográfico de D. Luís que legitima pretensões do ramo de Vassouras. Por Gilberto Freyre ele foi identificado como 'impetuoso pretendente imperial', em razão de seus manifestos, e como príncipe socialista, versão obliterada pela memória oficial da família acantonada na defesa da memória positiva e laudatória do Império, que se desdobra na divulgação de D.Luís como intelectual e viajante e na tentativa de perpetuar a alcunha dada a ele por Martim Francisco de Andrada - 'príncipe perfeito'. ${ }^{19}$

Uma biografia clássica segue a ordem cronológica e procura abordar exaustivamente os aspectos principais da vida e da obra de um indivíduo. Neste estudo sobre D. Luís a opção foi abordar alguns elementos seletivamente, segundo a relevância para a história política. Sua formação segundo os valores de uma sociedade de corte, seu ingresso no exército austro-húngaro sua atividade de escritor de livros de viagem e principalmente sua atuação como pretendente ao trono restaurado foram os eixos analíticos da trajetória biográfica. As relações entre o indivíduo e o coletivo adquirem diversos aspectos bastante ricos na sua trajetória biográfica, desde sua formação na 
infância e juventude, segundo habitus da sociedade de corte, até sua inserção no mundo das letras e da política.

A análise dos relatos de viagem de D. Luís solicita a compreensão de aspectos da sociabilidade em vigência em espaços de produção e difusão cultural onde atuou. Sua atividade de escritor de livros de viagem levou-o à inserção em redes de sociabilidade que desenvolveram estratégias de legitimação permeáveis ao jogo político mais amplo, difuso em matrizes institucionais, acadêmicas e governamentais. Entre elas, o Instituto Histórico e Geográfico Brasileiro constituiu campo específico dessa produção cultural da Primeira República, atuando no mundo das letras como caixa de ressonância da política interna e externa do período inclusive por meio de práticas que reuniam intelectuais em grupos rivais altamente competitivos pela obtenção e legitimação de prestígio.

D.Luís inseriu-se nessa agremiação em 1903, aos 25 anos de idade, após ter publicado Dans les Alpes e Tour d'Afrique. Se a primeira obra traz uma abordagem juvenil de suas experiências como alpinista, a segunda representou um salto no alcance de sua capacidade literária ao abordar a temática do imperialismo. Mas, além disso, contou certamente para sua admissão a qualidade de príncipe e não por acaso integrou o quadro de sócios juntamente com seu irmão mais velho D. Pedro de Alcântara, em continuidade à presença da família imperial na instituição: o avô, D. Pedro II, fundador e presidente perpétuo e o pai, Gaston d'Orléans, conde d'Eu, presidente honorário.

A Academia Brasileira de Letras também abrigou disputas e polêmicas do campo político e tornou-se um dos espaços de sociabilidade mais articulados da Primeira República. Após a morte de Machado de Assis, seu primeiro presidente, Rui Barbosa assumiu em 1908 a condução da entidade, imprimindo-lhe um sentido de republicanização. Campo social de grande prestígio, foi especialmente reconhecida no início do século como local por excelência de consagração dos intelectuais, construída por meio das intrincadas relações de poder ali vigentes.

Se de início o critério da familiaridade com as letras foi atendido na admissão de novos membros, logo esse requisito foi suplantado pelas exigências do poder, ao qual a agremiação se tornou extremamente vulnerável. Essas peculiaridades organizacionais e funcionais dos dois campos sociais e de sua interseção convergiram na candidatura de D. Luís ao ingresso entre os imortais. 
Além de reduto de notáveis a ABL também se constituiu como um campo social de natureza aglutinadora em torno da unidade nacional mobilizadora dos campos político e cultural no início da República. Apesar de concebida para permanecer um reduto intelectual afastado dos engajamentos políticos, a ABL não logrou permanecer nessa proposta dada a interligação dos campos sociais que resulta em pertenças múltiplas dos agentes sociais. Constituiu assim uma arena da política onde se manipulava a consagração no mundo das letras como recurso de visibilidade e legitimação do Estado republicano.

D. Luís nela pleiteou ingresso amparado por Oliveira Lima, um dos seus fundadores e ativo participante das cabalas eleitorais, cujos posicionamentos como eleitor acadêmico tiveram preferencialmente dois eixos cruzados, a inserção no Itamaraty e as relações com Pernambuco, seu estado natal e base política. Mas, por ocasião da candidatura de D. Luís, outros interesses estavam em jogo e traduziam sua aproximação da causa monarquista. Uma rede de relações intelectuais, de sociabilidade e políticas conduziu às estratégias de consagração que uniram Oliveira Lima e D. Luís, 'descoberto' a partir do estudo biográfico sobre o historiador-diplomata.

O confronto estabelecido por ocasião da candidatura patrocinada em 1914 por Oliveira Lima dividiu os acadêmicos e reproduziu questões da política interna brasileira, cujo eixo era o debate civilismo versus militarismo. Os embates acadêmicos repercutiram as correntes políticas mais fortes do momento. A compreensão dos interesses em jogo nas articulações eleitorais e de seu manejo pelas coteries é visível pela atitude de Rui Barbosa, seu presidente, em significativo ou enigmático silêncio diante do candidato imperial.

O episódio ocorreu em 1914, pouco antes da deflagração da Grande Guerra, no contexto da atuação política de D. Luís em 1912-1913. Autorizada literariamente pela publicação de À travers l'Hindo Kush e pelo grande sucesso de Sous la croix du sud, a primeira de suas obras a ser traduzida na íntegra para o português, sua candidatura não pode ser dissociada de um intento político. O projeto de estabelecer contatos com intelectuais brasileiros parece ter sido um plano traçado a partir de 1908, quando D.Luís correspondeu-se com Euclides da Cunha. Sobretudo, tratava-se de estratégia de propaganda da causa monárquica e de sua figura de herdeiro político de D. Isabel. Desde 1910 o príncipe mantinha trocas intelectuais e correspondência com Oliveira 
Lima. Tudo indica que a candidatura foi patrocinada e orientada pelo historiador e diplomata, como se vê pela carta enviada a ele por D. Luís em dois junho de 1914:

Seguindo o seu conselho escrevi há poucos dias ao Conde Afonso Celso (...). Resta a saber se semelhante passo seria acertado do ponto de vista político. Na verdade o meu provável fiasco seria atribuído às intrigas dos nossos adversários e o efeito produzido poderia nos ser desfavorável ${ }^{20}$.

Evidencia-se assim o caráter político de sua candidatura, que, se vitoriosa, lhe daria consagração literária e social, um título a mais de distinção de grande utilidade na propaganda da causa monárquica. Todo o desenrolar da campanha até o seu desfecho adverso esteve impregnado de conotação política. A candidatura teve início oficial com a carta de D. Luís a Rui Barbosa, então presidente da ABL: "Habituado a considerá-lo como o campeão infatigável das liberdades públicas no nosso país, espero que V.Ex. não negará a um exilado o favor e a honra que ele solicita".

Sem resposta, a carta produziu porém seu efeito, pois efetivou-se a candidatura ao ingresso na cadeira n. 6, cujo patrono era Casimiro de Abreu, fundada por Teixeira de Melo e ocupada até então pelo almirante Artur Silveira da Mota, barão de Jaceguai (1843-1914). O almirante entrara na Academia em 1907 apresentando a seu favor sua atuação como bibliotecário da Marinha e outros cargos ocupados na escola naval e sobretudo sua atuação na passagem de Humaitá, durante a Guerra do Paraguai. Além disso, é possível que atendesse aos interesses da facção monarquista. Jaceguai também integrara a coterie em que se inseriam os partidários da entrada do príncipe na academia. Na condição de seu adversário no pleito acadêmico apresentou-se o poeta, teatrólogo e engenheiro Goulart de Andrade.

A Oliveira Lima, ao apadrinhar a candidatura, coube o empenho junto aos confrades para obter votos. Mobilizou para isso sua rede de sociabilidade na qual Afonso Arinos, à época residente em Paris, desempenhou papel relevante por escrever aos membros da ABL solicitando votos para o príncipe ${ }^{21}$. Arinos era casado com Antonieta Prado, filha do conselheiro Antônio Prado e sobrinha do notório defensor do Império, Eduardo Prado. Jamais aderira à 
República e contava entre os amigos Coelho Neto, Carlos de Laet e Olavo Bilac. $^{22}$

Já Artur Orlando recusou seu voto em carta a Oliveira Lima, na qual deixou clara a conotação política da candidatura de D. Luís:

Meu voto para a Academia Brasileira de Letras recairá sempre sobre a pessoa cujo nome o Amigo indicar, exceto tratando-se de D.Luís, não por ódio ou antipatia individual, mas por motivo que se me afigura de ordem pública, se não constitucional ${ }^{23}$.

Por seu lado, D. Luís procedeu à costumeira busca de votos entre os acadêmicos, enviando-lhes pedidos formais. Primeiramente, a Afonso Celso em 31 de maio de 1914, ressaltando que o principal obstáculo consistia na questão política: temia que "os próceres do regime não tolerariam, por razões políticas”, sua eleição.

O pedido de voto a Coelho Neto foi reforçado por Afonso Arinos, que parece ter se empenhado bastante pela eleição:

Venho fazer-te um pedido, o primeiro que faço até agora, a tal respeito e para mim: rogo-te deixares de votar na próxima eleição da Academia, para eu não ver teu nome entre os adversários de D. Luís. Não fiz até hoje a ninguém pedido algum a favor de D. Luís. Fui portador de algumas cartas dele, mas não as entreguei pessoalmente e disso és testemunha. Quando ele se apresentou, nenhum candidato tinha aparecido, afirmando ele,desse modo, não se mostrar adversário de alguém.

Bem sei que o homem é o mais ingrato dos animais e o brasileiro o mais ingrato dos homens. É pois natural que o filho de quem sacrificou um trono pela redenção de uma raça; o neto de quem foi chefe de estado em país da América do Sul durante 49 anos e partiu para o exílio com as mãos limpas de sangue e de dinheiro- não ache guarida no seu país. O resultado da eleição pouco me importa. Será melhor talvez que o Goulart se eleja ${ }^{24}$.

A Rodrigo Octávio, o príncipe enviou também carta declarando suas intenções: Não ignoro as suas convicções republicanas, mas 
conhecendo também a sua imparcialidade e a sua mente generosa, bem sei que essas convicções jamais influirão no seu espírito, para o julgamento do valor literário dum candidato.

A vitória de Goulart de Andrade em 22 de maio de 1915 ocorreu após movimentação ampla dos bastidores e foi de vinte votos a nove. Mas onde estaria a razão de tanta resistência ao ingresso de D. Luís entre os imortais?

No dia 12 de maio de 1907, véspera da comemoração da Lei Áurea, aportava no ancoradouro da Ilha Fiscal, no Rio de Janeiro, o Amazone. A chegada tranquila do transatlântico à baía de Guanabara logo despertou um movimento no porto: lanchas conduziram a bordo pessoas ansiosas por cumprimentar o passageiro Luís Gabriel, ou melhor dizendo, o Príncipe D. Luís de Orleans e Bragança, que viajava incógnito. Há 17 anos ele não pisava em solo brasileiro, desde que aos 12 anos de idade, fora exilado com a Família Imperial na sequência do golpe que pôs fim à monarquia no Brasil.

Os titulares do Império - condes, marqueses, barões - recompunham no navio a velha corte, reunidos em torno do príncipe, o primeiro membro da casa de Bragança residente na França a tentar romper o bloqueio do banimento imposto à sua família pelo decreto 78-A emitido pelo governo provisório da República, em 1889. O acontecimento, segundo o testemunho de João do Rio, enviado a bordo como repórter do jornal $A$ Gazeta do Rio de Janeiro, movimentara a capital da República. A bordo acorreram monarquistas de chapéu alto e sobrecasaca, além de titulares do Império e muitos curiosos.

D. Luís considerava superada a restrição de entrada de sua família no país, não mencionada pela Constituição de 1891. Porém a intervenção do chefe de polícia da cidade frustrou seu plano. Na verdade, o próprio D. Luís havia previamente noticiado aos jornais sua intenção, provocando a reação do governo do presidente da República Afonso Pena, que, após ouvir Rui Barbosa, julgara prudente impedir seu desembarque para evitar acirramento dos ânimos anti-republicanos.

A tentativa do neto de D. Pedro II revelava-se um ato ambíguo ao mesclar a ousadia de tentar romper as barreiras restritivas à permanência de um membro da família imperial em território brasileiro, ainda não revogadas oficialmente, com as circunstâncias da visita. A negativa do príncipe em atribuir significado 
político à sua viagem desmentia-se pela presença entre os visitantes ilustres que subiram a bordo para o beija-mão, de políticos envolvidos com a causa da restauração do trono naqueles conturbados anos da jovem República. O visconde de Ouro Preto, o conde de Afonso Celso, o Conselheiro João Alfredo, o marquês de Paranaguá, Carlos de Laet testemunhavam com sua presença a persistência do movimento monarquista e sua fidelidade ao trono dos Bragança.

O episódio alcançou grande repercussão nos meios políticos. Não por mera coincidência a data do desembarque lembrava a figura da Princesa Isabel, residente na França. Os vivas a ela e à Monarquia retiravam a família imperial do esquecimento para colocá-la novamente no centro das atenções. A presença de um velho negro, que havia ensinado o príncipe a nadar em sua infância, era um elemento a mais do reavivar da memória dos brasileiros sobre seu passado monárquico.

Ao estabelecer contatos diretos com os militantes do movimento monarquista, com quem a família exilada mantivera correspondência desde o 15 de novembro, parecia empenhado em avaliar as possibilidades de um movimento restaurador. Tanto que na sequência, passou por Santos, cidade em que novamente se viu impedido de desembarcar pela polícia, para desgosto dos simpatizantes que ali acorreram para o beija-mão. Seguiu então viagem em direção à Argentina, ao Uruguai, Paraguai, Chile e Bolívia, relatando-a posteriormente no livro Sob o Cruzeiro do Sul.

No entanto, logo no ano seguinte, em 30 de outubro 1908, o casamento de seu irmão acabou alterando sua situação na linha da primogenitura dinástica pois dele resultou a renúncia de D. Pedro de Alcântara à condição de primeiro colocado na linha sucessória do trono, em caso de restauração. D. Luís passou então a ter maior envolvimento com os monarquistas, assumindo o papel de pretendente ao trono, em lugar da Princesa Isabel, que não se colocava como liderança explícita do movimento.

Porém a reação dos monarquistas aos atos de D. Luís nem sempre foi de aceitação. Saídos dos revezes sofridos pelos golpes e pelo apoio a revoltas desde o 15 de novembro, especialmente em 1900, 1902 e 1904, em 1907 estavam dispersos e desmobilizados. O Diretório Monarquista em São Paulo procurava sem êxito agregar militantes em torno da causa em refluxo e cogitava mesmo de sua dissolução enquanto grupo politicamente organizado, apto a participar das eleições com candidatos próprios. 
No ano seguinte, alçado á categoria de herdeiro presuntivo, D. Luís logo lançou um manifesto (janeiro de 1909) com a intenção de reunir os monarquistas dispersos, retomar a propaganda da causa e fundar novos centros de militantes. No entanto, pouco durou o enlevo de ambas as partes. Depositário de esperanças em 1907, em 1909 D. Luís entrou em atritos com os velhos chefes monarquistas que rejeitaram sua plataforma de governo por considerarem-na inaceitável em dois pontos: a defesa da federação e a proposta do serviço militar obrigatório.

O manifesto revelava o pensamento de um jovem enfronhado na política européia, nas principais tendências das monarquias européias (Inglaterra, Alemanha e Bélgica) e interessado em renovar a causa monárquica no Brasil. Para isso, incorporava ao seu discurso temas em evidência na cultura política da Primeira República. Porém foi rejeitado pelos velhos líderes, que agarrados á tradição confiavam mais na princesa Isabel do que nas novidades propostas por seu filho impetuoso. Mesmo assinado por como 'D.Luís de Bragança', retirando de seu nome a referência aos Orleans que poderia estigmatizá-lo pela acusação de estrangeirismo que pesava sobre seu pai e sua família, a cisão foi inevitável. Falava português arrastado, com sotaque francês e o serviço militar prestado na academia militar de Viena foram impedimentos para que ele se colocasse à frente do Diretório Monarquista, que preferiu manter-se fiel à evocação do Império de D. Pedro II. Seus intentos de se tornar presidente do Diretório soçobraram em 1909 e ele retirou da cena pública até 1913, quando com novo manifesto recolocou-se no centro dos debates políticos.

O manifesto de 1913 foi lançado também em meio a uma crise política que acompanhou a campanha civilista para eleições presidenciais, da qual saiu vitorioso o marechal Hermes da Fonseca, ao derrotar o adversário Rui Barbosa. Nessa ocasião, o manifesto de D. Luís foi utilizado pelas forças políticas em meio aos intensos debates parlamentares. Nele, a exemplo do manifesto de 1909, chama a atenção um item na época pouco comentado, mas que se tornaria ponto importante na visão construída sobre D. Luís e de sua peculiaridade no movimento monarquista: a menção ao chamado 'problema operário'.

Argumentando em favor do regime monárquico, o manifesto louvava as monarquias européias por desenvolverem políticas de proteção aos operários. A identificação do príncipe como socialista distorce sua proposta política que 
pretendia evitar o agravamento das condições de vida dos operários e sua adesão ao socialismo ou ao comunismo. Essa era de resto a postura defendida pela doutrina social da Igreja Católica que desde a encíclica Rerum novarum procurava responder aos problemas decorrentes dos avanços na industrialização na Europa. A proposta de uma monarquia amparada em legislação social, adaptando o regime aos tempos, revelava um observador atento da sociedade de sua época, na qual o movimento operário confrontava as duras condições de vida dos trabalhadores das fábricas. O Brasil, recém-saído da escravidão, já experimentava também nessa época os efeitos da nascente industrialização, as greves e a organização dos operários segundo as propostas socialista e anarquista. Ultrapassando a perspectiva liberal, que considerava a chamada questão operária uma 'questão de polícia', D. Luís propunha uma nova política, preventiva, capaz de garantir a 'aliança entre o capital e o trabalho' e portanto a harmonia social.

D. Luís não mais retornaria ao Brasil. Em 1920, faleceu após enfermidade longa que o atingira durante a Primeira Guerra, experiência que relatou em seu Diário de Guerra. Não alcançou a revogação do banimento da família imperial, nem o repatriamento dos restos mortais de D. Pedro II e D. Teresa Cristina, em 1922. De seu casamento com a Princesa D.Maria Pia de Bourbon-Sicília, da casa real das Duas Sicílias nasceram três filhos, dos quais D.Pedro Henrique assumiu o papel de pretendente ao trono em caso de eventual restauração.

À guisa de conclusão pode-se constatar que a construção de biografias pelo historiador coloca em questão direcionamentos e limites a serem observados já no momento da escolha do personagem, motivada por sua atuação ou por qualidades que possam estabelecer identificações projetivas importantes. O cultivo do gênero comporta em primeiro lugar a sedução do historiador pelo personagem biografado, por sua vida de alguma maneira considerada excepcional e digna de ser o centro de um estudo, por revelar aspectos ainda não abordados pela historiografia voltada para o macro ou por permitir a visualização das tensões entre indivíduo e sociedade. Biografar indivíduos vivos ou não? Qual o grau de exaustão do 'eu' que a biografia comporta? Como biografar sem criar 'tipos'? Como biografar sem cair nos elogios ou julgamentos? Como tratar a questão ética, que independentemente das ameaças no âmbito da justiça precisa ser levada em conta quando o historiador se apropria da memória do biografado, expondo seus segredos, suas mazelas, suas contradições? 
Ao longo desta pesquisa as reflexões permitiram a constatação de que não há como eludir a forma narrativa e cronológica que permite acompanhar a trajetória do personagem e estabelecer "marcos temporais entre acontecimentos e história individual" "25. Tal constatação não implicou porém o uso exclusivo do método discursivo, factual, centrado na existência individual, mas foi combinado a outros, especialmente na transdisciplinaridade, visando uma história analítica e compreensiva.

A análise levou em conta tanto o campo político específico, onde são produzidos problemas, programas, análises, comentários, conceitos e ações específicas, como outros campos que deram uma dada configuração às trajetórias cruzadas de Oliveira Lima e D. Luís de Orléans e Bragança: o campo da produção literária e histórica, o campo das associações de intelectuais e sobretudo o campo da política. Todos eles constituíram instrumentos de legitimação, bem como de disputa entre posições rivais, pois a sociabilidade está longe de pautar-se por relações harmoniosas. Ela é um campo de luta, disputa, alianças, rupturas que abrangem tanto relações políticas propriamente ditas como as tradições específicas do campo intelectual.

O resultado permitiu verificar como ambos os biografados, dadas as posições nos diversos campos sociais ou espaços de sociabilidade, construíram trajetórias convergentes e teceram relações em diferentes espaços de sociabilidade, com alocações e deslocamentos pelos campos sociais e políticos. 


\section{Notas e Referências}

1 Jean ORIEUX. "A arte do biógrafo". In: Georges DUBY et al. História e Nova História.

2 Benício Bisso SCHMIDT. Construindo biografias. In: Estudos Históricos, Rio de Janeiro, 9, 1997, p. 8.

3 Benício Bisso SCHMIDT. Construindo biografias. In: Estudos Históricos, Rio de Janeiro, 9, 1997, p. 13.

4 Franco FERRAROTTI. Histoire et histoires de vie, 1990, p. 49.

5 Franco FERRAROTTI. Histoire et histoires de vie, 1990, p.51.

6 Marieta de Moraes FERREIRA e Janaína AMADO. Usos e abusos da História Oral. $8^{\text {a }}$.ed., Rio de Janeiro: Fundação Getúlio Vargas, 2006.

7 Pierre BOURDIEU e J.C. PASSERON. O ofício de sociólogo. $6^{\mathrm{a}}$ ed., Rio de Janeiro: Vozes, 2004.

8 A.L. MACHADO NETO. Estrutura social da república das letras. São Paulo: EDUSP, 1973.

9 Norbert ELIAS. A sociedade de corte. Rio de Janeiro: Zahar, 2001, p. 83.

10 Pierre BOURDIEU. O poder simbólico. $14^{\mathrm{a}}$ ed., Rio de Janeiro: Bertrand Brasil, 2006.

11 Angela de Castro GOMES. História e historiadores: a política cultural do Estado Novo. Rio de Janeiro: FGV, 1996, p.41.

12 R. GLEZER. O fazer e o saber na obra de José Honório Rodrigues: um modelo de análise historiográfica. São Paulo: FFLCH-Usp, 1976. Tese (Doutorado), p.96.

13 A.L. MACHADO NETO. Estrutura social da república das letras. São Paulo: EDUSP, 1973, p.41 e126

14 Max LECLERC. Cartas do Brasil. São Paulo: Companhia Editora Nacional, 1942 . In: Emilia Viotti da COSTA. Da monarquia à república. Momentos decisivos. São Paulo:UNESP, 2007.

15 Roderick BARMAN. Princesa Isabel do Brasil. São Paulo: Editora da Unesp, 2005, p.300-01.

16 A sete de setembro de 1920, revogada a lei do exílio (banimento) da Família Imperial, teve início o movimento de retorno de seus remanescentes, do traslado dos despojos de D.Pedro II e D.Teresa Cristina, no bojo das comemorações do Centenário da Independência. 
17 Carta de Alberto Rangel a Afonso de Taunay, sete de agosto. A correspondência de Afonso de Taunay foi obtida com a colaboração de Karina Anhezini.

18 Idem.

19 Gilberto FREYRE. Ordem e progresso. São Paulo: Global, 2004.

20 Carta de D.Luís a Oliveira Lima, Boulogne-sur-Seine, 2/6/1914.

21 Carta de Arinos de Melo Franco a Oliveira Lima, Paris, 3/7/1914.

22 Afonso ARINOS FILHO. Prefácio. In: Afonso ARINOS. Pelo sertão: histórias e paisagens. 4. ed., Rio de Janeiro: ABL, 2005.

23 Carta de Artur Orlando a Oliveira Lima, Recife, 14 /6/1914.

24 Carta de Afonso Arinos a Coelho Neto, São Paulo, Chácara do Carvalho, 28/4/1915.Id, p. 292-3.

25 Alzira ABREU. Dicionário biográfico: a organização de um saber. Caxambu: II Encontro Anual da ANPOCS, 1998. 